the centre of philosophical concern" (page 184).

\section{MARIE FOX}

Faculty of Law, University of Manchester

\section{Ethics in Medicine}

\author{
Milton D Heifetz, Amherst, New \\ York, Prometheus Books, 1996, 264 \\ pages, $£ 16.99$.
}

It is a curious fact. A surgeon can make a stab at writing a book on ethics that is at least as competent as most such, whereas a philosopher, unless perhaps he is John Locke, can hardly make a stab at surgery and expect to be averagely efficient. This book, by a top neurosurgeon, is, though full of bad things, well up to the prevailing professional standard, and will be every bit as useful to the student as what is usually set. I shall comment on the initial stance adopted by the author, and then briefly discuss a single chapter, rather than skim over the whole book.

Dr Heifetz has considerable hopes for the study of ethics. He thinks, with unrealistic optimism, that the subject might possibly improve the conduct of those who study it (page 9). To achieve this improving end, $\mathrm{Dr}$ Heifetz invites us to "stand back and assess our situation, free from the burdens of tradition, dogma, or gut reaction that limit our thinking" (page 10). That sounds well. But is this possible, and insofar as it is possible, would it be wise? It is after all rather a Cartesian project, and look where such a thing landed Descartes! In my experience most people, including philosophers, are unshakeably convinced that they should not poison an aunt for a legacy. Never the less they tend to give a rather feeble account of why this is so. Fortunately for aunts, they do not straightaway free themselves from the burdens of their traditional belief. The phrase "gut reaction" is vulgar and unhelpful. The thought that one should not poison one's aunt is not typically accompanied by visceral upset. We should simply talk about our convictions sometimes fallible - which we struggle further to understand, and leave our innards out of it.

In this book Dr Heifetz concentrates on the usual life and death issues. This seems to me a good choice. Something momentous is at stake. We are spared endless wander- ings in the desert of informed consent and other empty places. (Dr Heifetz dwells briefly on informed consent in "The Doctor-Patient Relationship", one of his better chapters, obviously touched by his own experience.) There is an attempt here to find some general rationale or framework, rather than simply to discuss "case studies". This too sounds promising. But Dr Heifetz, as perhaps we all do, tends to promise more than he can deliver.

He begins his account by pointing out, as a kind of axiom, that everyone wants to avoid being harmed (page 20). Unfortunately, he immediately gives a bad account of what harm is. "It is the judgement of the person acted upon that determines whether or not harm does or does not exist" (page 24). "It exists whenever an act is considered unacceptable by the individual acted upon" (page 23). All this is obviously wrong. He says that "no one willingly accepts harm" (page 24). To make this even plausible one would have to add "under that description". People willingly accept what is in fact harmful to themselves all the time. But it is not true even with this qualification. It is absurd to suppose that if a political prisoner gives himself to be shot in place of a companion, the bullets "really" do no harm after all. Should the prison authorities perhaps be congratulated for managing to murder without harming? Of course I am assuming that "willingly" does not here mean something like "joyfully".

The axiom is, then, that people do not like to be harmed. From this we somehow derive a teaching: "Individual freedom is inviolate as long as others are not harmed in the exercise of that freedom" (page 25). This is a familiar enough claim. But it is unthinking. It is often all right to close off possibilities open to others, even where what they propose to do is unobjectionable. We do so a hundred times a day. Anyone who sits in a chair prevents everyone else sitting in it at that time. The first person to $\mathrm{X}$ stops everyone else - countless millions from being the first to $\mathrm{X}$. Dr Heifetz often expresses fine liberal sentiments on our behalf. "The individual does not exist for the benefit of others - in fact the converse is the case" (page 181). I wondered what the converse might be.

"The essence of ethical problems" is then said to be "the balancing of relative harms" (page 26). Does this mean that the solution to the problem is simply to balance harms? This would be an unsympathetic interpretation for what might be called harm balanc ing can be very evidently unjust. On only has to remember the killing-one? to-save-five cases discussed in a thou sand ethics classes. The sympatheti reader is then left with a problem of understanding this claim.

The upshot of all these deliberation is a little disappointing. One emerges with four principles "which should beे balanced in each situation" (page 32) Naturally, one gets a feeling of deja vufu (The four principles turn out to be the familiar ones, with "the public inter est" taking the place of distributivis justice.) On the positive side, this approach would seem attractively powerful, that is to say powerful if what it permits, and would probabl $\$$ enable a doctor to avoid most of the uncomfortable injunctions which threaten to embarrass him or hep True enough, there is a mention here of "firmly grounded precepts", an $\vec{b}$ this might cause anxieties (page 32,00 But then we are told reassuringly that there are no "clear cut rules" (page 33). This should make the boo appealing - at least, if it were not also said in so many other books. But on⿷ wonders whether one wouldn't fin more illumination by scrapping the framework and returning to the cas studies.

So much for the theoretical frame work. Since we must be selective, let us see how Dr Heifetz handles the topic of abortion. It is interesting to note how little the framework seems to be called upon. There is indeed novel contribution here to this much discussed problem. Abortion cannoर be murder, we are told, for murder, is the moral rather than the legal sense is to kill with malice and no one feet malice towards babies, fetuses o whatever (page 123). This is a suno prising (and useful) account of muro der. It would not count as murder tक kill an aunt for her money if one had nothing particularly against one aunt. This would be especially obve ous if one was also thinking of giving some of the proceeds to good causest Given this account of murder, there is not much left to discuss about aboo tion. We soon find that despite the fact that everyone, no matter the stafof of his development, has the same rights, (page 149) we can more or les go along with the status quo, parentg choice and all that. This is a litte unexpected, since Dr Heifetz is nof. only convinced about "equal rights in the sense explained, but is keen on the idea of "as if" autonomy in cases 
of incompetence. What would an unwanted infant demand if it were competent and informed? This is a pretty restrictive test. Few of us want to be poisoned or decapitated, even when facing a difficult future. (If I read him aright, Dr Heifetz argues in favour of possibly lethal fetal experimentation, on the ground that an unwanted fetus which was shortly going to be poisoned etc by a doctor would have nothing to lose and in the circumstances, as a friendly fellow, would willingly give the go-ahead (page 190-4).

In regard to abortion, Dr Heifetz could have reached his usefully permissive teaching in another way, making use of his framework. Why doesn't he tell us that a fetus or indeed a born baby cannot be harmed by being killed (despite his casual assumption that this is possible) (pages 192-3). It is hard to see the point of defining harm as he does if he is not prepared to put the definition to good use.

\section{CHRISTOPHER MILES COOPE}

School of Philosophy, University of Leeds.

\section{The Quality of Death: Euthanasia in Australia}

Edited by Lynda Burns and Ian Hunt, Centre for Applied Philosophy, Flinders University, Adelaide, Australia, 1996, 113 pages, A $\$ 12.00+$ P\&P.

In 1996, the Legislative Assembly of Australia's Northern Territory (representing less than two per cent of the nation's population) en-acted provisions for medically assisted euthanasia. However, the national parliament overrode the legislation a few months later. These are matters of passion and controversy. It is alleged that "euthanasia is commonly practised" by doctors in Australia (although the reliability of the survey evidence on that point has been queried); the topic commands front pages of the tabloids and opinion polls are said to reveal that more than 75 per cent of Australians think "we give our dogs a kinder death" than the unassisted, drawn-out death allowed to the uneuthanased.
The Quality of Death includes presentations from the kind of meeting to which up to 300 people will make night-time journeys across cities, plus some more considered pieces on philosophical and legal issues surrounding the practice of, and arguments for and against, euthanasia. It raises, incidentally, some interesting issues about the way bioethics is done.

Brian Stoffell is a capable philosopher and a good teacher, able to excite students on the history of ideas about the meaning of death and the character of human reactions to it. His piece for the evening audience of 300 , slightly amended here, begins with a distinction between controversies (the exchange of controvertible or contestable claims about a matter), debates (in which "people are expected to ... disagree heartily") and discussions (in which people concentrate sincerely on sorting out the relevant questions). The bulk of his chapter is an attack on the apparent inconsistencies of those who argue against assisted suicide or euthanasia on deontological grounds. It is an attack which is easy to make: of course "killing is wrong", as a blanket prescription, runs up against cases where life may seem not worth sustaining; of course people whose life seems to have lost any content worth sustaining remain the people whose autonomy we would have asserted the day before the content evaporated. Having said those things, however, not everything has been said about dying and human experience.

Roger Hunt is a caring palliative physician with a strong, even crusading, view that euthanasia is a proper part of the repertoire of hospice care. $\mathrm{He}$ has published descriptive studies of changes in the place of death of Australians and some of that social analysis appears briefly and rather scrappily in his chapter on "Clinical, Ethical and Legal Aspects of Euthanasia". Hunt also hops into the potentially silly side of religiously-driven defences of the life-at-any-price variety, but his account of his opponents is not fair, in conventional scholarly terms, and utilitarians who are dubious about euthanasia might complain about his treatment of them, too.

Alnis Vedig gives a short account of "Euthanasia in Hospitals" with the brisk medical pragmatism of the head of an intensive care unit, making the cases a bit more punchy than the otherwise similar studies which abound in textbooks on bioethics. Vedig does not mount a strong argument but he does make the telling observation that: "The extent of suffering, if one is doomed and likely to be removed from the lottery of continued lifesustaining therapy, will be influenced by ... quality of life issues, presence of advocates ..., and, in many hospitals, the availability of critical care beds, etc - certainly not just medical assessment of the odds of a successful outcome."

Margaret Otlowski's substantial chapter on "Active Voluntary Euthanasia: A Legal Perspective" gives up-to-date information on what the law is and how it is applied in Australia, the United States, the United Kingdom and the Netherlands. She argues, in the process, that the law should be reformed "to end the legal and moral danger posed by the gap between what doctors do in practice and what they are permitted to do in law". Her conclusion touches upon what some regard as an important middle way in the politics of euthanasia: "By ... reforming the law to permit medical assistance in dying in carefully controlled circumstances, there is, in the long run, far greater opportunity to regulate the practice and safeguard the interests of both patients and doctors than if these practices are hidden."

Grant Gillett is a New Zealand neurosurgeon who publishes a good deal on bioethics, with an emphasis on the phenomenology of moral judgment. His chapter here, on "The Pause and Euthanasia Law Reform", elaborates his experience of the moment in a judgment to withdraw treatment when "the sheer importance of what one was deciding about caused a hesitation in the decision". He uses phenomenological approaches and language drawn from virtue ethics, which is currently a significant minority position in Australian bioethics. One appeal of that approach, in Gillett's hands, is that it makes room for the notion of proportionality which a good casuist would use in conjunction with distinctions such as killing and letting die, ordinary and extra-ordinary means or double effect.

Stoffell and Hunt, by comparison with Gillett, seem to skate over that nuanced approach in haste to assert that the autonomy of the dying person trumps all other values. If we allow that analytical philosophy can easily demonstrate the logical silliness of distinctions such as killing and letting die or ordinary and extra-ordinary means, are the people who use those distinctions wrong or merely using 